\title{
NEXOS ENTRE MÉXICO Y EUROPA CENTRO-ORIENTAL
}

\author{
MÓNIKa SZENTE-VARGa
}

Universidad de Panonia

\begin{abstract}
The first diplomatic and consular relations were established between Mexico and the Habsburg Empire in the 1800 's, motivated basically by commercial reasons and dynastic interests. These got to an abrupt end with the execution of Emperor Maximilian in Querétaro in 1867, and diplomatic relations were resumed only decades later, in 1901, which is, in fact, our starting point. This essay examines the development of diplomatic relations between Mexico and Central-Eastern Europe from the beginning of the $20^{\text {th }}$ century until nowadays. It is divided into chronological chapters, where we study bilateral relations in the coordinates of the following periods: beginning of the century, the period between the two world wars, the Second World War, Cold War and recent years. The investigation in based on documents of the Ministry of Foreign Affairs of Mexico (SRE-AHD) and of the Hungarian National Archive (MOL).

Principalmente con base en las colecciones del Acervo Histórico Diplomático de la Secretaria de Relaciones Exteriores de México (SRE-AHD) y del Archivo Nacional Húngaro (MOL) ${ }^{1}$, y en el marco cronológico que abarca desde principios del siglo XX hasta la actualidad, este ensayo estudiará el desarrollo de las relaciones diplomáticas entre México y la región de Europa Centro-Oriental. Los orígenes de dichos nexos se remontan al siglo XIX cuando los primeros contactos diplomáticos y consulares fueron creados entre México y la entidad más grande en la región, el Imperio Habsburgo, motivados desde el viejo continente por intereses comerciales así como por razones dinásticas. Durante lo que vino a ser el segundo imperio en México, ${ }^{2}$ encabezado por Maximiliano de Habsburgo entre 1864 y 1867, el Imperio Habsburgo, liderado por Francisco José, hermano mayor de Maximiliano, abrió una legación en la Ciudad de México (1864) y un consulado en Veracruz (1865).
\end{abstract}

\footnotetext{
1 Magyar Országos Levéltár.

${ }^{2}$ Brasil y México fueron los únicos paises cuya independencia no significó automáticamente la creación de una república, sino que tuvieton también periodos bajo régimen imperial.
} 


\section{Relaciones diplomáticas entre 1901 y 1918/19}

Las oficinas establecidas en los 1860 tuvieron una vida muy breve debido a la pérdida del poder y al subsiguiente fusilamiento de Maximiliano. Varias décadas tuvieron que transcurrir para que los vínculos diplomáticos entre los Habsburgo y México, rotos desde la caida del segundo imperio, fueran restablecidos finalmente en $1901 .^{3}$ Las razones para el reacercamiento incluían el creciente interés de la Monarquía Dual Austro-Húngara hacia América Latina, sobresaliendo como atractivos especiales los abundantes yacimientos minerales y el deseo de la Monarquia de buscar nuevos mercados, y tal vez nuevos potenciales destinos para su corriente emigratoria. México, por su parte, consideraba a Austria-Hungria un país clave en el mantenimiento del status quo en Europa. Además, hay que recordar que eran los años del porfiriato, y existía una innegable atracción hacia Europa y lo europeo, y el viejo continente se había convertido en sinónimo de lo sofisticado, de lo desarrollado y de lo avanzado. No tener lazos diplomáticos con un país de alrededor de $700.000 \mathrm{~km}^{2}$ en esta Europa hubiera sido una contradicción.

Naturalmente, también desempeñaron papeles importantes en la reanudación de las relaciones bilaterales, lo que podríamos calificar como factores de corte personal. Por ejemplo, la amistad entre Porfirio Díaz y el Conde Carl Khevenhüller-Metsch, ${ }^{4}$ originada en la década de mil ochocientos sesenta, cuando el aristócrata europeo estaba en México como uno de los voluntarios de Maximiliano. ${ }^{5}$

En 1901 se inauguró en Querétaro la capilla expiatoria de Maximiliano y llegaron a México para la ocasión varias personalidades, entre ellas el propio Conde Carl Khevenhüller-Metsch. Su presencia facilitó las conversaciones, que ya con toda seguridad se encontraban en fases avanzadas, puesto que ese mismo año los dos países decidieron reanudar sus lazos diplomáticos. México abrió una representación en Viena y la Monarquía Dual una legación en la Ciudad de México. Durante las casi dos décadas que funcionó esta última oficina, Austria-

\footnotetext{
${ }^{3}$ SRE-AHD, exp. 17-19-69.

4 (1840?-1905). El diario de las experiencias del príncipe en México fue publicado en 1983 en Austria bajo el titulo Mit Kaiser Max in Mexiko, seguido por una edición mexicana: Brigitte HAMANN, Con Maximiliano en México. Del diario del príncipe Carl Khevenbïller, 1864-1867, México, FCE, 1989.

${ }^{5}$ Sobre los voluntarios húngaros que acompañaron a Maximiliano, véase Katalin JANCSÓ, "Magyarok Habsburg Miksa, mexikó császárának szolgálatában. Külföldi csapacok Mexikóban a II. császárság idején", Tiszatäj, 2011/1, 72-79.
} 
Hungria tuvo en total seis representantes ${ }^{6}$-entre ellos 2 barones y 3 condes-, todos diplomáticos con bastante experiencia profesional que llegaron a pasar solamente un tiempo corto en México - un año o dos- con la excepción del último enviado, Kálmán Kánya, quien permaneció en el puesto casi cinco años y medio. ${ }^{7}$ México por su parte no necesariamente nombró diplomáticos profesionales. La importancia del primer enviado, por ejemplo, no se derivó de sus conocimientos profesionales sino más bien de su parentesco, ya que era cuñado del Presidente Díaz. Desafortunadamente esto también implicó que se trataba de una persona bastante mayor, que falleció muy pronto, en 1902 . De hecho, aparentemente el puesto en Viena no trajo mucha suerte para los representantes mexicanos, puesto en el que del total de cuatro enviados, tres murieron durante su gestión. ${ }^{8}$

Después de la muerte de Miguel Covarrubias en 1917, México no mandó nuevos representantes sino que, ahorrando gastos, encargó los asuntos de la Monarquía al enviado en Alemania, ${ }^{9}$ cambiando así a una representación concurrente, una clara señal de su decrecida atención. De hecho, la segunda mitad de los años 1910 trajo consigo un creciente desinterés en ambas partes sobre sus contactos de ultramar y un aumento de atención hacia los asuntos internos, con una concentración en su propio entorno, en México por la Revolución y en la Monarquía por el conflicto armado estallado en 1914. La Primera Guerra Mundial no solamente "distrajo" a Austria-Hungría, sino que tuvo otras consecuencias. Por ejemplo, mostró ante el mundo que la Monarquía no era tan poderosa como se pensaba, puesto que necesitaba el apoyo de Alemania, volviéndose cada vez más dependiente. (Esto con toda seguridad desempeñó igualmente un papel importante en la decisión mexicana de 1917 de dejar únicamente una representación concurrente.) Por otra parte, la guerra obstaculizó gravemente el transporte trasatlántico de personas, productos e información por años. Los lazos bilaterales entre México y la Monarquía se

6 En orden cronológico: Gilbert Hohenwart, Jaroslav Wiešnievski, Karl Giskra, Miksa Hadik, Ferenc Riedl y Kálmán Kánya. Fuente: SRE-AHD, expedientes personales. Variaciones de nombres: Giskra, Charles de; Riedl, Franz von, y Hadik de Futak, Max.

7 Para más detalle, véase Ádám ANDERLE-Monika KOZÁRI, A Monarcbia utolsó követe. Kánya Kálmán Mexikóban, 1914-1919, Szeged, $1^{2}$ ed., 1990, $2^{2}$ ed., 1996, 120. En español: Un bíngar en el México revolucionario, México, Edamex, 1999, 220 págs.

${ }^{8}$ José De Teresa y Miranda (m. 1902), Jesús Zenil (m. 1905) y Miguel Covarrubias (m. 1917). Sólo Gilberto Crespo y Martinez continuó su carrera, y se hizo enviado extraordinario y ministro plenipotenciario de México en Washington (1911), ocupando así uno de los encargos más importantes de su país. Fuente: SRE-AHD, expedientes personales de: De Teresa y Miranda, José (5-13-33); Zenil, Jesús (L-E-1347-8); Covarrubias, Miguel (27-18-210) y Crespo y Martínez, Gilberto (1-19-11).

${ }^{9}$ Rafael Zubaran Capmany. 
aflojaron, pero no se soltaron hasta finales de la década. Es interesante mencionar que, en varios casos, el Servicio Exterior y las representaciones austro-húngaras sobrevivieron la disolución de la Monarquía, incluso durante todo un año. La legación en la Ciudad de México, por ejemplo, sólo se cerró en el verano de 1919.

\section{Relaciones diplomáticas entre 1919 y 1945}

A principios de los años veinte, en lugar de nexos entre México y Europa Centro-Oriental, debemos hablar más bien de la falta de ellos. Las representaciones de la Monarquía ya no funcionaban, y el establecimiento de nuevas relaciones tardaba, porque México, tras la Revolución, y particularmente la región de Europa Centro-Oriental, tras la guerra, necesitaban un período de recuperación.

Los cambios europeos fueron impresionantes. La Primera Guerra Mundial ocasionó la caída de los Romanov en Rusia, de los Hohenzollern en Alemania y de los Habsburgos en Austria, así como la disolución de la Monarquía Dual. Se efectuó una mayor reorganización de fronteras en la región, con cambios tanto en el tamaño como en la cantidad de los países. El número creció espectacularmente al aparecer y/o reaparecer entidades independientes en lugar . de los grandes imperios. Para 1920 encontramos los siguientes estados en Europa Centro-Oriental: los tres países bálticos que se independizaron de Rusia; la restablecida Polonia, que había desaparecido de los mapas europeos a finales del siglo XVIII; la recién formada Checoslovaquia, de composición multiétnica; otro estado multiétnico, el Reino de Serbia, Croacia y Eslovenia, desde 1929 llamado Yugoslavia; Hungría, Rumanía, Bulgaria y Albania. Vale la pena mencionar que, entre Lituania, Polonia y el mar Báltico, se encontraba un enclave alemán, Prusia Oriental.

\section{Checoslovaquia}

Entre todos los países mencionados, el capital inicial de Checoslovaquia era el más significativo. Heredó una quinta parte del territorio de la Monarquía Austro-Húngara, pero con aproximadamente el $70 \%$ de su capacidad industrial. ${ }^{10}$ Consecuentemente, la recuperación del país fue rápida después de la guerra, y ya para 1924 alcanzó los niveles de producción de la pre-guerra. La estable situación económica permitió que el país se abriera y pudiera crear conexiones con lugares relativamente lejanos, como los países latinoamericanos.

\footnotetext{
${ }^{10}$ En algunas ramas este porcentaje era aún más alto, por ejemplo, $90 \%$ de la industria vidriera y de porcelana, $80 \%$ de la industria azucarera y $75 \%$ de la industria textil y quimica. Fuente: Emil PALOTÁS, Kelet-Európa története a 20. század elsô felében, Budapest, Osiris, 2003, 265.
} 
En México, por otra parte, obviamente despertó interés Checoslovaquia, como el país más desarrollado y más industrializado de la región. Las relaciones diplomáticas fueron establecidas hace 90 años, en 1922.

\section{Hungria}

La disolución de la Monarquia Dual significó la desaparición de la unidad económica que representaba y la ruptura de las ligas tradicionales de intercambio, todo lo cual afectó mucho a Hungría. Su situación se complicó aún más con las pérdidas de territorio que implicó el Tratado de Versalles. Se necesitó una completa reestructuración interna. El resultado fue crisis económica, inflación, desempleo y una significativa reducción en el nivel de la vida en general. Hungría solamente pudo salir adelante a través de un préstamo internacional, que hizo posible una estabilización de la moneda y de la vida económica para 1924-25.

El establecimiento de los contactos diplomáticos húngaro-mexicanos fue precedido por la normalización de los vínculos consulares en 1925, cuando Hungría abrió un consulado general honorario en la Ciudad de México, ${ }^{11}$ eligiendo como cónsul a Comelius Gertz. ${ }^{12}$ Es importante mencionar que no hubo necesidad de que México abriese una oficina en Budapest, puesto que su consulado en la capital húngara, fundado todavía en tiempos de AustriaHungría, siguió funcionando a pesar de la Primera Guerra Mundial y aún después, a pesar de la inestabilidad y la violencia que caracterizaban al país, especialmente entre 1918 y 1922 . El consulado sobrevivió, entre otras cosas, la disolución de la Monarquía Dual y la formación de la Hungría independiente, la revolución burguesa de 1918, la Revolución Bolchevique de 1919, el terror rojo, la llegada de las fuerzas rumanas hasta la capital, la toma del poder por las fuerzas conservadoras, el terror blanco, el regreso a la forma de estado de reino (esta vez sin rey), dos intentos furtivos de Carlos IV de Habsburgo por recuperar su trono húngaro, y el Tratado de Trianon. Sobra decir que la situación económica tampoco era muy prometedora. No obstante, el cónsul, Dr. János Sömjén, ${ }^{13}$ siguió activo. Su persona y gestión -que duró hasta su muerte en 1929- dieron continuidad a los lazos entre México y Hungría.

\footnotetext{
${ }^{11}$ MOL, K106 73cs.

12 (1867, Tetenbüll - 1944, Ciudad de México). Residente en México desde 1890, fue empleado y más tarde director de la compañia Sommers \& Hermann Co. Fungió también como presidente de la Cámara Mexicana de Industriales y fue uno de los fundadores del Banco de México. Adoptó la nacionalidad húngara en 1934.

13 (1871-1929). Abogado, intérprete oficial de las legaciones de Francia y de España en Budapest, vicecónsul honorario de México (1910-12) y cónsul honorario de México en Budapest (1912-29). Dotado con un don extraordinario para los idiomas, manejaba, aparte del húngaro, el
} 
Las relaciones diplomáticas fueron formalizadas sólo hasta 1926, y se materializó el nombramiento de embajadores concurrentes, László Széchényi ${ }^{14}$ por parte de Hungria, con oficina en Washington, y José Manuel Puig Casauranc ${ }^{15}$ como embajador de México, desde Roma. Sin embargo, el conflicto cristero puso obstáculos a la continuidad en el desarrollo de dicho acercamiento. Los eventos en México recibieron bastante publicidad negativa en Hungría, ${ }^{16}$ especialmente en la prensa católica húngara. Hubo inclusive una manifestación en la capital húngara en pro de los católicos mexicanos y, finalmente, para 1928 el conflicto cristero se convirtió en un asunto político. ${ }^{17}$ Las comarcas mandaron una solicitud al Parlamento pidiendo la intervención del gobierno húngaro ante la Sociedad de Naciones. ${ }^{18}$ La propuesta llegó a la cámara alta y fue aceptada en versión modificada, solicitando meramente que el ministro húngaro del exterior diera a conocer la protesta de la cámara cuando y como él considerase pertinente. La decisión del ministro, de informar al Vaticano sobre la declaración, cuadró armónicamente con la política exterior húngara, que se ajustó -sin ser muy activa- a la política del Vaticano con respecto a los eventos mexicanos. Esto sin embargo obstaculizó el desarrollo de los nexos estatales húngaro-mexicanos, y resultó en la postergación del nivel que habían alcanzado los contactos bilaterales hacia julio de 1926. Así, por el momento hubo solamente embajadas concurrentes, ${ }^{19}$ y un consulado en cada país. Éstos últimos fueron cerrados en 1941, debido al desarrollo del conflicto militar.

francés, el español, el alemán, el inglés y el italiano. En 1910 publicó un diccionario bajo el título Diccionario bringaro-francés, especializado en los campos de derecho, administración puiblica, comercio y asuntos financieros, acompañado por ejemplares de formatos oficiales franceses. Tras su muerte, la familia solicitó y obtuvo el manejo del consulado.

${ }^{14}$ Aristócrata húngaro, nacido en 1879. Presidente de la Liga Nacional para la Protección de los Niños (Országos Gyermekvédelmi Liga), delegado del gobierno y miembro perperuo de la cámara alta del Parlamento, entre otros cargos. Desde 1921 hasta 1934 fue enviado extraordinario y ministro plenipotenciario en Washington y desde 1926 esturo acreditado ante el gobierno mexicano en forma concurrente.

15 Nació en 1888 en Ciudad del Carmen, Campeche. Cirujano, diputado, senador, Ministro de Educación y de Industria y diplomático. Embajador de México en Italia (concurrente en Hungria desde 1926), en los Estados Unidos y en Argentina. Murió en 1939 en la Ciudad de México.

16 Véase Mónilsa SZENTE-VARGA, "El reflejo de la primera guerra cristera de México en Hungria", Acta Hispanica VII, 2002, 119-135.

${ }^{17}$ El objetivo declarado fue la protección de los católicos mcxicanos pero naturalmente existió también un objetivo oculto, lograr que Hungria tuviera un rol en el escenario internacional.

${ }^{18}$ Archivo de la comarca de Borsod-Abaúj-Zemplén, Hungria, Documentos del ayuntamiento de la ciudad de Miskolc, 17542 / 1928.

19 Embajadores mexicanos concurrentes en orden cronológico: José Manuel Puig Casauranc, Bernardo Gastélum, Ezequiel Padilla, Manuel de Negri, Primo Villa Michel, Manuel Téllez, 


\section{Polonia}

La situación de Polonia tampoco resultó ser fácil tras la Primera Guerra Mundial, puesto que se trata de un país restablecido después de más de un siglo de inexistencia, con un territorio para organizar y administrar muy grande (sexto en Europa y primero en la región) y sin frontera oriental fija para 1918, lo que implicó la prolongación de los actos bélicos. Los límites entre Polonia y Rusia fueron finalmente decididos mediante la guerra de 1919-1921, que terminó con el Tratado de Riga. Debido a los factores anteriormente mencionados, la recuperación económica tardó en llegar hasta la segunda mitad de la década de los 1920, y como uno de los resultados de ello, los vínculos consulares y diplomáticos entre Polonia y México se dieron relativamente tarde, a finales de la década. Las relaciones fueron formalmente establecidas el 26 de febrero de $1928 .^{20}$ En el mismo año se abrió el consulado general de Polonia en la Ciudad de México, y en 1929 fue inaugurado el consulado de México en Varsovia. Aparte, se sabe que los enviados extraordinarios y ministros plenipotenciarios Tytus Filipowicz por parte de Polonia y Rodolfo Nervo por parte de Méxicohicieron entrega de sus respectivas cartas credenciales en 1930, ya como representantes residentes. ${ }^{21}$

\section{Otros paises de la región}

Por el momento no es posible ofrecer una vista general sobre los lazos entre el resto de los países del área y México, debido a que no en todos los casos existen investigaciones latinoamericanas sistemáticas, y consecuentemente faltan estudios sobre el tema o, en otros casos, aunque existan estudios, estos están escritos no en español sino en las lenguas maternas de los investigadores, y por ende no son necesariamente accesibles para los demás latinoamericanistas de la región.

En general, se puede decir, que estos países - principalmente agrícolastuvieron una recuperación bastante lenta y difícil después de la Primera Guerra Mundial, lo que les dejó un período muy corto de estabilidad y desarrollo antes de pasar nuevos apuros, esta vez traídos por la gran crisis financiera mundial, que llegó y azotó la región de Europa Centro-Oriental principalmente en la primera mitad de los treinta. La precaria situación económica, así como la falta de dinero, naturalmente disminuyeron los deseos de mantener tratos con países

Leopoldo Ortiz y Eduardo Vasconcelos. Embajadores húngaros concurrentes: László Széchényi (1926-1934), János Pelényi (1934-1941) y György Ghika (1941).

${ }^{20}$ Información proporcionada por cortesía de la Lic. Magdalena Díaz Téllez y la Lic. Ingrid Alcántar Orizaba, SRE, Dirección General para Europa.

${ }^{21}$ Datos tomados de Relaciones México Polonia 1921/1989. Cronologia y docunzentos, México, SRE, 1989, 18-19. 
tan lejanos como México. El nuevo curso económico favorable, que se dio solamente desde alrededor de mediados de los años treinta, fue acompañado por una creciente atención hacia Europa y en particular hacia la propia región, así como por una preparación para una posible nueva guerra. Las conexiones con América Latina claramente no eran una prioridad. Se sabe, por ejemplo, que Yugoslavia no estableció nexos diplomáticos con México hasta 1946, ${ }^{22}$ y Albania mucho más tarde, en 1974. En el caso específico de Rumanía y Bulgaria, dos reinos encabezados por dinastias de origen alemán -los Hohenzollern y los SaxCoburgo, respectivamente- los vinculos diplomáticos con México fueron creados después de la gran crisis financiera pero antes del segundo conflicto armado mundial. La fecha del establecimiento de las relaciones diplomáticas rumano-mexicanas, que se efectuaron a nivel de legaciones, encabezadas por ministros extraordinarios y plenipotenciarios, fue el 20 de julio de $1935 . .^{2.3}$ Esto podría parecer bastante tardío, considerando que se trata de un pais neolatino con un idioma muy similar, inclusive podríamos decir, un país hermano; pero se puede entender si tomamos en cuenta las realidades económicas. Similarmente, los lazos búlgaro-mexicanos se iniciaron en la segunda mitad de la década, a partir del 6 de enero de $1938,{ }^{24}$ ya en tiempos de la dictadura Real. ${ }^{25}$

\section{Segunda Guerra Mundial}

La Segunda Guerra Mundial alteró de una manera significativa los contactos entre México y la región, que al tomar caminos divergentes llegaron a separarse definitivamente, pero no cuando el propio conflicto estalló en el viejo continente o cuando los paises de Europa Oriental entraron en la guerra, sino cuando el continente americano, más precisamente los Estados Unidos, fueron afectados por el conflicto armado. Tras el ataque contra Pearl Harbor, México rompió sus relaciones diplomáticas con Japón. Cuando Alemania e Italia declararon la guerra a los Estados Unidos, México contestó cortando sus nexos con dichos países. Y cuando Bulgaria, Hungria y Rumanía declararon la guerra a

22 Jefes de Misión de México ante Serbia y Montenegro, incluida Yugoslavia. Página de la Embajada de México en Serbia y Montenegro, http://www.mexican-embassy.org.rs/Embassy _list_ambassadors.html, bajado de Internet el 2 de septiempre, 2012.

23 México y Rumanía celebran 75 años de relaciones diplomáticas, página de la Embajada de México en Rumania, 20 de julio 2010, http://www.embamex.ro/esp/actual_75ani.hum, bajado de Internet el 2 de sepriempre, 2012.

24 Información proporcionada por cortesía de la Lic. Magdalena Diaz Téllez y la Lic. Ingrid Alcántar Orizaba, SRE, Dirección General para Europa.

25 En referencia a la dictadura ejercida por un monarca, ya sea rey, o zar, como en el caso particular de Bulgaria, fenómeno común en la región entre las dos guerras mundiales, que se dio en Yugoslavia, Rumanía y Bulgaria. 
los Estados Unidos con la idea de apoyar a las declaraciones alemanas e italianas, México no tardó en romper sus lazos diplomáticos con ellos. Por lo tanto quedó sin contacto oficial con una parte importante de Europa Centro-Oriental a partir de diciembre de 1941.

Los vinculos con Polonia también se veían amenazados por el conflicto bélico. Luciano Joublanc Rivas, encargado de negocios ad interim de México, se vio obligado a trasladar la legación, y llegó así a principios de septiembre, ya tras la ocupación alemana, a la ciudad de Kazimierz Dolny. ${ }^{26}$ El representante mexicano finalmente abandonó el país con rumbo a Rumanía el 19 de septiembre, dos días después de la invasión soviética. Los contactos bilaterales se continuaron entonces a través de las representaciones polacas en el extranjero. México por su parte, reconoció inmediatamente al gobierno polaco en el exilio, con residencia en Londres, y en 1941 nombró a su representante ante dicha entidad. ${ }^{27}$ De hecho, la relación fue tan amistosa que el General Wladislaw Sikorski, ${ }^{28}$ comandante en jefe de las fuerzas polacas y presidente del gobierno polaco en el exilio, visitó México durante la guerra, en diciembre de 1942 , y negoció la llegada de refugiados polacos. ${ }^{29}$ Los números originalmente propuestos -20 mil, reducidos más tarde a 5 mil- no se cumplieron, y arribaron finalmente alrededor de 1500 personas, las cuales fueron instaladas en un campamento en Santa Rosa, Guanajuato, cerca de la ciudad de León. ${ }^{30}$ En total, las relaciones polaco-mexicanas se pueden considerar ininterrumpidas aún en los años de la guerra.

El caso de Checoslovaquia fue un poco diferente, porque los nexos diplomáticos con México sí quedaron rotos, tras la ocupación alemana el 15 de marzo de 1939. Luego de una corta interrupción, se reanudaron en 1942, cuando México, similarmente a Gran Bretaña, Estados Unidos y la Unión Soviética, reconoció el gobierno checoslovaco en el exilio, liderado por Eduard Benes ${ }^{31}$ y ubicado en la capital británica. A pesar de la falta de tiempo y dinero, tanto el gobierno checoslovaco en el exilio como el polaco establecieron legaciones en México durante la guerra, para cuyo funcionamiento se basaron en

\footnotetext{
${ }^{26}$ Ciudad histórica a la orilla del Vistula, ubicada en la parte central de la actual Polonia.

27 Alfonso de Rosenzweig-Díaz, en calidad de enviado extraordinario y ministro plenipotenciario.

28 (1881-1943).

29 Relaciones México Polonia 1921/1989. Cronologia y documentos, 31-32.

${ }^{30}$ Para más detalle, véase Gloria CARREÑO y Celia ZACK DE ZUKERMAN, El convenio ilusorio. Refugiados polacos de guerra en México (1943-47), México, [s.n.], 1998.

31 (1884-1948).
} 
parte en la inmigración de sus nacionales asi como en la llegada de refugiados, como lo fue en aquel momento la periodista-escritora Lenka Reinerova. ${ }^{32}$

'Trabajaba en la embajada del gobierno checoslovaco en el exilio, ubicada en México. Naturalmente no babia mucho dinero, [precisamente] por ser un gobierno en el exilio, y la embajada era muy pequeña. Habia un embajador, un canciller, yo y otro bombre. Eso era todo. [...] Trabajé en la embajada desde el dia de su apertura. Primero que nada, tuve empleo. Segundo, tuve un trabajo que me gustaba hacer, y mucho, porque sentia que en México se encontraba de todo y eso era bueno, mientras en Europa babia una guerra. Mi familia estaba allá. [...] En la embajada pude hacer algo, muy poquito, muy poguito, pero algo." 33

Al escribir sobre los contactos mexicano-checoslovacos, no se puede dejar sin mencionar que en el mismo año del restablecimiento de los vínculos diplomáticos, ocurrió la masacre nazi en el pueblo de Lidice, iniciada el 10 de junio de 1942, con la completa destrucción del pueblo y eventualmente la muerte de casi todos sus habitantes. Como símbolo de solidaridad con los checoslovacos,

"... bubo poblados que tomaron el nombre Lidice en diferentes paises. México fue el primero. Habia un pueblo que se llamaba San Jerónimo Aculco y le adicionaron el nombre Lidice. ." El primer pueblo en el mundo. ${ }^{35}$ Tipico de los mexicanos." 36

La transición al final de la guerra, de los nexos con el gobierno en el exilio a los contactos con los gobiernos formados en los países liberados, fue mucho más sutil en el caso de Checoslovaquia, puesto que E. Beneš, el líder en el exilio, regresó a su patria tras la guerra y desempeñó un papel muy importante en la vida política hasta su muerte en 1948. En el caso de Polonia, el reconocimiento del gobierno provisional formado en el pais, trajo consigo la terminación de los vínculos con el gobierno polaco en el exilio, pero no la ruptura de las relaciones entre México y Polonia, que seguian y siguen ininterrumpidas desde su establecimiento en 1928.

32 (1916-2008). Fue la continuadora y tal vez el último miembro de la tradición literaria judeoalemana de Praga, caracterizada por literatos como Franz Kafka, Max Brod y Egon Erwin Kisch. Principalmente escribió en alemán.

33 Entrevista de la autora a Lenka Reinerova, en inglés, realizada el 23 de agosto de 2004 en Praga. Traducción de la autora.

34 San Jerónimo Lidice, Distrito Federal.

${ }^{35} \mathrm{La}$ fecha que se tiene es 30 de agosto de 1942. Con esto, México fue efectivamente el primer país en América Latina, antecediendo a Cuba, Brasil, Ecuador, Colombia, Venezuela y Chile que también se unieron al esfuerzo de preservar la memoria de Lidice. Pero habria que aclarar que México no fue el primero en el mundo, porque Stern Park Gardens, en Illinois, tomó el nombre de Lidice el 12 de julio de 1942. Fuente: Ministerio de Relaciones Exteriores de la República Checa. http://wuww.mzv.cz/jnp/cz/o_ministerstru/organizacni_struktura/utvary_mzv/specializovany _archiv_mzx/ fondy_archivu/iidice_1939_1945.html, bajado de Intemet el 2 de sepuiempre, 2012.

${ }^{36}$ Entrevista de la autora a Lenka Reinerova. 


\section{Relaciones diplomáticas entre 1946 y 1989}

La división del mundo en dos bloques opuestos después de la Segunda Guerra Mundial, las mutuas sospechas entre ellos, la carrera armamentista, y en general la tensión internacional, no ayudó en absoluto al restablecimiento y/o estrechamiento de lazos entre México y la región de Europa Centro-Oriental. Esta última resultó además muy afectada por la guerra, puesto que varios territorios habían sido campos de batalla por un tiempo considerable y esto llevó consigo una significativa pérdida tanto humana como material. El conflicto bélico fue seguido por una aguda crisis económica, cuando obviamente la reconstrucción y la estabilidad interna tenían prioridad sobre una posible apertura de política exterior. Además, las posibilidades de dicha apertura eran muy limitadas, debido a la influencia de la Unión Soviética, a través de la presencia del Ejército Rojo, y de los partidos comunistas, que en la segunda mitad de los 1940 tomaron el poder en todos los países de la región. Ya para 1949 se completó la formación del bloque socialista. Europa quedó dividida políticamente en Este y Oeste, categorización en la que no cabía el concepto de Europa Central. En un mundo bipolar hubo una Europa bipolar.

No obstante, los países socialistas nunca fueron tan homogéneos como lo pintaba la propaganda de la guerra fría y casi inmediatamente aparecieron las primeras grietas, como por ejemplo en el caso de Yugoslavia. Se trata de un país donde los comunistas eran populares, puesto que tuvieron un papel muy importante en la resistencia y en las fuerzas de liberación, y porque contaban con un líder carismático: Josip Broz Tito. ${ }^{37}$ Por lo tanto no necesitaban el apoyo -político y militar-de Moscú para llegar al poder, lo que lograron ya para 1945. Autoconfidente, el liderazgo yugoslavo siguió su propio camino hacia el socialismo, lo que trajo consigo relaciones muy tensas con la Unión Soviética y con otros países socialistas. A pesar de que hubo un cierto reacercamiento tras la muerte de Stalin, Yugoslavia no dejó de comportarse de una manera no conformista: no fue integrante del Pacto de Varsovia, en el Comecon fungió únicamente como miembro asociado, ${ }^{38}$ y fue uno de los fundadores del movimiento de los no-alineados. Esto último implicó contactos exteriores diversificados y amplios, y un interés especial hacia el tercer mundo. ${ }^{39}$

\footnotetext{
$37(1892-1980)$.
}

${ }^{38}$ Existieron varios tipos de relaciones con el Comecon: miembro completo, miembro asociado, observador y cooperador no socialista (por ejemplo, México).

${ }^{39}$ Tito visitó México en 1963 y 1974. Durante su gestión, estuvieton de visita en Yugoslavia los presidentes Adolfo López Mateos (1964) y Luis Echeverría (1974). 
Varios de los antecedentes mencionados asi como la ubicación estratégica de Yugoslavia en el Mar Adriático y su potencial económico, obviamente no pasaron desapercibidos en México, para cuyo gobierno era además urgente contar con una representación en la región. Los lazos diplomáticos yugoslavomexicanos fueron establecidas inmediatamente después de la guerra, el 24 de mayo de $1946,{ }^{40}$ y a principios de la década de 1950 se abrió una embajada mexicana en Belgrado, la única en aquel momento en la región de Europa Centro-Oriental.

Aunque los nexos polaco-mexicanos y checoslovaco-mexicanos no se rompieron con la integración de ambos paises al bloque socialista, obviamente sí se enfriaron. Solamente después de la muerte de Stalin, fueron elevados los vínculos al nivel de embajadas, para finales de los años cincuenta. Por lo tanto, a partir de la década de 1960, México contaba con tres embajadas en la región, en Yugoslavia, Checoslovaquia y Polonia. La reanudación de los contactos con Bulgaria, Hungría y Rumanía -países que se encontraban en bandos opuestos con México tanto en la Segunda Guerra Mundial como en la guerra fría- todavía se hizo esperar más de una década. El marco para el arreglo de dichos acuerdos fue proporcionado en parte por el descongelamiento del ambiente internacional a principios de 1970, el interés mundial suscitado por los Juegos Olímpicos de 1968, organizados por México, el crecimiento de los lazos comerciales, y la política exterior del presidente Luis Echeverría, orientada a ampliar las relaciones de su país, que resultó en la apertura de varias embajadas, por ejemplo en Vietnam y China. En cuanto a la región que nos ocupa, el restablecimiento de las los nexos entre México y Rumanía en 1973 fue seguido un año más tarde por la reapertura de contactos diplomáticos con Hungría y Bulgaria. Finalmente, el 15 de octubre de 1974, quedaron formalizados los vínculos entre México y el país más aislado y al mismo tiempo menos desarrollado de la región: Albania. Así, a partir de 1974 México tenía ya lazos diplomáticos con todos los paises de Europa Centro-Oriental. En poco tiempo, con la apertura de oficinas en Rumanía y Hungría, sus embajadas en la región fueron aumentadas a cinco, número que sigue sin cambio en la actualidad.

\section{Hungria}

El 14 de abril de 1974 México y Hungria acordaron establecer relaciones diplomáticas a nivel de embajadas. Un mes más tarde se abrió la embajada de Hungria en la Ciudad de México, dirigida primero por el Dr. János Király,

\footnotetext{
40 Relación bilateral, página de la Embajada de México en Serbia http://portal.sre.gob.mx/serbia /index.php?option=displaypage\&Itemid $=117 \&$ :op $=$ page\&:SubMenu=, bajado de Internet el 2 de septiempre, 2012.
} 
encargado de negocios ad interim. ${ }^{+1}$ En 1975 fueron nombrados los primeros embajadores, Ulises Schmill Ordoñez, concurrente desde Viena, y Zsiva Peják, quien fue directamente a la Ciudad de México, donde le encontramos a la cabeza de la representación húngara a partir del 2 de julio de 1975. ${ }^{42}$ Todavía transcurrió otro año antes de la apertura de la embajada de México en Budapest, que se efectuó finalmente el 30 de septiembre de 1976. El primer embajador mexicano residente en Budapest fue Roberto de Negri Yberri.

\section{Situación actual}

La décadas de los 1980 y 1990 trajeron consigo una extraordinaria transformación política y económica en la región. Se fue el Ejército Rojo, cayó el sistema unipartidario que marcó las cuatro décadas que siguieron a la Segunda Guerra Mundial, se efectuó el cambio hacia la economía de mercado, etcétera. En total, el bloque socialista quedó desmantelado. El fuerte debilitamiento de la influencia local de la Unión Soviética - pais que desaparece como tal en 1991- y el resurgimiento del nacionalismo en Europa Centro-Oriental fueron factores primordiales para la multiplicación de países en la región. Reaparecieron los tres estados bálticos ${ }^{43}$ y se disolvieron los países multiétnicos creados tras la Primera Guerra Mundial: Checoslovaquia de una manera pacífica y Yugoslavia, tras varias sangrientas guerras internas. ${ }^{44}$

La serie de cambios arriba mencionados naturalmente afectaron la política exterior mexicana, y trajeron consigo, por ejemplo, el reconocimiento de los países recientemente creados o resurgidos y el establecimiento de nexos diplomáticos bilaterales, si bien tratando de evitar nuevos gastos. Así, se organizaron nuevas concurrencias, para cuyas ubicaciones se trataron de aprovechar estratégicamente las cinco embajadas mexicanas existentes en la

${ }^{41}$ Levente GAJDÓCSI-András KISS (eds), Hungarian Embassies and other Diplomatic Missions (19451978), Budapest, Cold War History Research Center, 2005. http://www.coldwar.hu/html/en /finding_aids/hungary/emb_hun.html, bajado de Internet el 2 de septiempre, 2012.

42 Ibidem.

${ }^{43}$ Puesto que ya habían existido ciertos lazos bilaterales en el período de entreguerras, cuando dichas repúblicas eran independientes -se sabe por ejemplo que México y Lituania establecieron vínculos diplomáticos en 1938- en relación con los nexos entre México y estos paises tal vez sea mejor hablar de una reanudación, que de hecho se dio en la segunda mitad de 1991, aún antes de la disolución formal de la Unión Soviética.

44 El cambio más reciente de la región fue la declaración unilateral de Kosovo sobre su independencia en febrero de 2008. A partir de entonces unos noventa países reconocieron a Kosovo como pais. México no ha hecho una declaración oficial ni a favor, ni en contra, pero su actuación -su apremio para que los kosovares y los serbios entablen diálogos, y su insistencia sobre el apego a la ley internacional- hacen pensar que está más bien opuesto a la independencia de Kosovo. 
región, pero sin sobrecargarlas. Para ello, y como siempre que se organiza una representación concurrente, era indispensable tomar en cuenta distancias, accesibilidad, fronteras en común, afinidades, hostilidades, e inclusive fricciones entre estados, para evitar potenciales tensiones y tratar de asegurar el adecuado funcionamiento de la concurrencia. Por ejemplo, al disolverse Checoslovaquia, no era evidente de inmediato que la relación entre la República Checa y Eslovaquia seria necesariamente buena. Consecuentemente, para Eslovaquia, no era conveniente crear la concurrencia desde la embajada mexicana en Praga, ni desde la oficina en Budapest, puesto que las relaciones húngaro-eslovacas eran tensas, en gran parte por la situación de la minoría húngara residente en Eslovaquia. La solución fue recurrir a una embajada que se encontraba cerca, pero fuera de la región, es decir, libre de las posibles tensiones locales: la embajada de México en Austria. De hecho, varias de las concurrencias se formaron de una manera similar, desde embajadas que no se ubican en la región, si bien geográficamente se encuentran cerca, por ejemplo, Suecia y Finlandia. ${ }^{45}$ Tal vez en el futuro las concurrencias serán modificadas, y en algunos casos, sustituidas por representaciones residentes, como en el caso de Eslovenia y los países bálticos. El estrechamiento de contactos bilaterales, sin embargo, actualmente ya no es la única, ni necesariamente la manera más favorecida de acercarse a la región.

Un desarrollo muy importante que tenemos que tomar en cuenta al estudiar las relaciones exteriores del área es que al desaparecer las antiguas organizaciones como el Pacto de Varsovia y el Comecon, se formaron nuevos vínculos - militares, económicos, políticos y culturales- por una parte, a través del crecimiento de organizaciones ya existentes (Unión Europea, OTAN), y por otra, al crearse nuevas formas de cooperación. Entre estas últimas figuran por ejemplo, el Acuerdo Centroeuropeo de Libre Cambio (CEFTA), ${ }^{46}$ la Iniciativa Centroeuropea (CEI), el Grupo de Visegrád (V4), la Cooperación Económica del Mar

\footnotetext{
45 A continuación se proporciona una lista de las concurrencias que se manejan especificamente en relación con los paises de la región que nos atañe. 1) DESDE REPRESENTACIONES QUE SE ENCUENTRAN FUERA DE LA REGIÓN: La embajada de México en Austria maneja las concurrencias para Eslovenia y Eslovaquia. La oficina en Finlandia cubre Estonia, pais cuyo idioma pertenece también a la familia lingüística urálica. Suecia maneja los otros dos paises bálticos, Letonia y Lituania. La embajada en Italia también se encarga de los asuntos en Albania. 2) DESDE REPRESENTACIONES QUE SE ENCUENTRAN DENTRO DE LA REGIÓN: La embajada en Hungria lleva las concurrencias con Croacia -país vecino y con el que comparte una larga historia común-y Bulgaria. A su vez, la oficina en Belgrado cubre Bosnia-Herzegovina, Macedonia y Montenegro. Las relaciones diplomácicas entre México y Montenegto fueron establecidas el 5 de junio de 2007. ${ }^{46}$ Las siglas de las organizaciones se anotan en inglés por ser más comunes en los medios.
} 
Negro (BSEC), el Consejo de los Estados Bálticos (CBSS) y la Iniciativa de Cooperación de Europa Sudoriental (SECI), en su mayoria formadas en los 1990.

La búsqueda de contactos con organizaciones -regionales o internacionalesen lugar de países específicos, podría ser una opción atractiva para México, ya que de esta manera tiene la posibilidad de manejar entidades más grandes $y$ abarcadoras. La mayoría de los paises de Europa Centro-Oriental ya son miembros de la Unión Europea y otros esperan poder acceder.

México tuvo sus primeros acercamientos con la Comunidad Europea en una fecha temprana, a principio de los años 1960, sin embargo éstos se volvieron intensos solamente unas tres décadas después, en conexión con la creación del Tratado de Libre Comercio de América del Norte (TLCAN). México necesitó a la Comunidad para aligerar los posibles efectos negativos del tratado, como una dependencia aún más de los Estados Unidos, mientras la Unión buscó la manera de poder quedarse en el mercado mexicano bajo condiciones favorables, e incluso aprovechar el futuro tratado para poder moverse dentro del área desde México. Este interés mutuo tuvo manifestaciones importantes antes y también después de la firma del TLAN. Ejemplos de lo anterior incluyen la apertura de una misión de la Comunidad Europea acreditada en México en 1989 y la visita de Jacques Delors, presidente de la Comisión Europea, a México en 1993. La declaración común entre la Unión Europea y México se efectuó después de que el TLAN entrara en vigor, y cuando, además, México se encontraba en una situación económica precaria. La declaración subrayó la importancia de ampliar contactos, que se concretizaron en el Acuerdo de Asociación Económica, Concertación Política y Cooperación, que México firmó con la Unión Europea. Por ser este tan amplio, también se hace referencia a él como acuerdo global, o un acuerdo de cuarta generación. Fue el primero de este tipo que la UE firmó con un país latinoamericano. Después de México seguirían Chile y Brasil.

Aunque existen acuerdos entre la UE y países latinoamericanos, la atención de los países de Europa Centro-Oriental ha bajado considerablemente hacia el subcontinente. Mientras la integración a la Unión Europea de gran parte de los estados de la región que nos ocupa incrementó el interés mexicano, también distrajo a los propios países de Europa Centro-Oriental, que concentran ahora su política exterior mucho más hacia Europa que hacia América Latina. El internacionalismo de los tiempos socialistas desapareció (factor político), surgieron problemas financieros (factor económico), y la atención, por ejemplo hacia México, decreció visiblemente. No obstante, entre las misiones extranjeras acreditadas en México encontramos las de Bulgaria, Eslovaquia, Estonia, Hungria, Lituania, Polonia, República Checa, República Eslovaca, Rumanía, Serbia y la de la 
Delegación de la Unión Europea, ${ }^{47}$ entidad de la que estos países, con la excepción de Serbia, forman parte. México está presente solamente en 5 de estos países con oficinas residentes, cubriendo el resto de los no pocos estados con concurrencias, y cuenta además con una embajada ante la Unión Europea. Es precisamente en el marco de dicha organización que México probablemente reforzaría sus lazos con Europa Centro-Oriental, y para los países de la región la UE es una oportunidad de volver la mirada hacia América Latina. ${ }^{48}$

\footnotetext{
47 Situación al 6 de junio de 2012. Página de la Secretaria de Relaciones Exteriores de México, http: / $/$ www.sre.gob.mx/index.php?option=com_content\&view=article\&id=1034\&Itemid $=320$, bajado de Internet el 3 de septiembre de 2012.

${ }^{48}$ Principales fuentes archivísticas: Archivo de la comarca de Borsod-Abauj-Zemplén, Miskolc, Hungria: documentos del ayuntamiento de la ciudad de Miskolc 17542/1928; Acervo Histórico Diplomático de la Secretaria de Relaciones Exteriores, Ciudad de México: expedientes personales de los representantes diplomáticos y consulares; Arcbivo Nacional Hingaro, Budapest: documentos relacionados con las representaciones húngaras en México: K63 162cs, K63 163cs, K106 53cs 18t, K106 72cs 33t, K106 73cs, K106 74cs 33t, K106 97cs 59t.

Bibliografía recomendada: Ádám ANDERLE-Monika KOZÁRI, A Monarchia utolsó követe. Kánya Kálmán Mexikóban, 1914-1919, Szeged, $2^{2}$ ed., 1996; Gloria CARREÑO y Celia ZACK DE ZUKERMAN, El convenio ilusorio. Refugiados polacos de giserra en México (1943-47), México, [s.n.], 1998; Levente GAJDÓCSI-András KISS (eds.), Hungarian Embassies and other Diplomatic Missions (1945-1978), Budapest, Cold War History Research Center, 2005; Brigitte HAMANN, Con Maximiliano en México. Del diario del principe Carl Khevenbüller, 1864-1867, México, FCE, 1989; Katalin JANCSÓ, "Magyarok Habsburg Miksa, mexikó császárának szolgálatában. Külföldi csapatok Mexikóban a II. császárság idején”, Tiszatáj, 2011/1, 72-79; Emil PALOTÁS, KeletEurópa története a 20. sqázad elsö felében, Budapest, Osiris, 2003; Relaciones México-Polonia 1921/1989. Cronologia y documentos, México, SRE, 1989; Mónika SZENTE-VARGA, "El reflejo de la primera guerra cristera de México en Hungria”, Acta Hispanica, VI, 2002, 119-135; Mónika SZENTEVARGA, Migración buingara a México entre 1901 y 1950, Mexikó, BUAP-SZTE, 2007.
} 